\title{
Distribution System Loss Reduction through Hybrid Heuristic Technique
}

\author{
John Wiselin \\ Deptt of Electrical and Electronics Engineering, \\ Satyam College of Engg \& Tech, \\ Aralvaimozhi, \\ TN, India
}

\author{
Perumal Shankar \\ The Principal, \\ M.E.T. Engineering College \\ Chenbagaraman puthoor
}

\begin{abstract}
This paper proposes a hybrid technology to solve the distribution system reconfiguration problem. The technology with the mixture of Plant Growth Simulation Algorithm (PGSA), Greedy and heuristic based fuzzy operation has been proposed. The optimization approach based on PGSA provides detailed description on switch states for calculation. The inclusion of Greedy with PGSA improves the efficiency of optimization by identifying the best loop sequence. Furthermore, the heuristic fuzzy has been introduced with PGSA and Greedy for handling constraints amid optimization. With the use of proposed algorithm, the system loss has been reduced convincingly without compromising the power flow constraints. The effectiveness of the proposed approach is demonstrated by employing the feeder switching operation scheme to IEEE 33 bus distribution system and 83 bus Distribution system of Taiwan Power Company.
\end{abstract}

\section{Keywords}

distribution network, heuristic fuzzy, greedy, PGSA, reconfiguration, restoration

\section{INTRODUCTION}

Feeder reconfiguration is a very important tool to operate the distribution system at minimum cost and improve the system reliability and security. The reconfiguration of a distribution system is a process, which alters the feeder topological structure by changing the open/close status of the switches in the distribution system. The presence of high number of switching elements in a radial distribution system makes the network reconfiguration a highly complex combinatorial, nondifferentiable and constrained non-linear mixed integer optimization problem. Also, the number of variables varies with respect to the size of the system. The distribution system with ' $n$ ' switches will have ' $n$ ' variables. The demand for a radial operation also makes the mathematical model more difficult to represent efficiently and codification of a solution becomes difficult when metaheuristic techniques are employed.

Civanlar et al.[1] conducted the early work on feeder reconfiguration for loss reduction. In [2], Baran et al. defined the problem of loss reduction and load balancing as an integer programming problem. Aoki et al. [3] developed a method for load transfer, in which the load indices were used for load balancing. In Shirmohammadi and Hong [4], the solution method starts with a meshed distribution system obtained by considering all switches closed. Then, the switches are opened successively to eliminate the loops. Other methods, such as mathematical programming techniques [5-7], expert systems [8-10] and optimization algorithm [11] have been proposed in recent years. In [12], the solution procedure employing heuristic rules and fuzzy multiobjective approach are developed to solve the network reconfiguration problem. Wang and Cheng [13] present an approach to minimize the total system losses by using the PGSA to optimize the network configuration of the distribution system while satisfying some constraints. Even though, the above method gained encouraging results, the loop sequence for optimization has been not clearly shown and they have sequenced the loop randomly for optimization. In paper [14], the algorithm uses neural network which needs to be trained for large distribution system. In [15] and [16], evolutionary programming is employed for optimizing distribution network. In [17], equivalent network for distribution network has been formed aiming in reducing the time consumption for optimization. The above methods have gained encouraging results in solving the problem of distribution network optimization, but also inadequacy in some respects. Most of the algorithms usually spend much of the computation time in solving real large-scale systems, and include some external parameters such as barrier factor, crossover rate, mutation rate, etc.

It is difficult to determine the external parameters in many cases, and they affect the calculation efficiency and convergence, which probably cause occasional computational difficulty. This paper presents hybrid technology for optimization based on PGSA, Greedy and heuristic fuzzy, which improves the efficiency and provides opportunity of going with more constraints. The highlights of the proposed approach concerning previously published algorithms are that it evades heavy numerical computing, less time consuming, easy to adapt to any kind of radial distribution network such as single and multi feeder system, unambiguous definitions on reconfiguration procedure.

\section{PROBLEM FORMULATION}

In this paper, the objective is to minimize the system power loss under a certain load pattern through network optimization while electrical and operational constraints are met, that is the process of altering the topological structures of distribution network by changing the open/close status of switches so as to minimize total system real power loss. The objective function of the problem is ,

$$
\text { Minimize Ploss }=\sum_{j=1}^{n l} \mathrm{R}_{j} \frac{\mathrm{P}_{\mathrm{j}}^{2}+\mathrm{Q}_{\mathrm{j}}^{2}}{\mathrm{~V}_{\mathrm{j}}^{2}}
$$

where,

$\mathrm{P}_{\text {loss }}$ is the total real power loss of the system.

The apparent power transported by the branch must satisfy the branch's capacity. The voltage magnitude at each bus must be maintained within limits. These constraints are expressed as follows:

$$
\begin{aligned}
& S_{i} \leq S_{i, \max } \\
& V_{i, \text { min }} \leq V_{i} \leq V_{i, \text { max }}
\end{aligned}
$$

Furthermore, the radial structure of network must be maintained, and all loads must be served. 


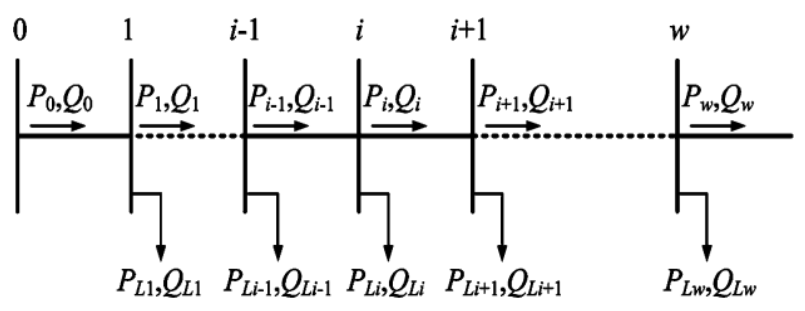

Fig. 1 Single line diagram of a main feeder

A set of feeder-line flow formulations is employed. Considering the single line diagram in Fig. 1, the following set of recursive equations is used to compute power flow:

$$
\begin{aligned}
& P_{i+1}=P_{i}-P_{L i+1}-R_{i, i+1} \frac{P_{i}^{2}+Q_{i}^{2}}{V_{i}^{2}} \\
& Q_{i+1}=Q_{i}-Q_{L i+1}-X_{i, i+1} \frac{P_{i}^{2}+Q_{i}^{2}}{V_{i}^{2}}-V_{i}^{2} \frac{y_{i}}{2}
\end{aligned}
$$

$$
V_{i+1}^{2}=V_{i}^{2}-2\left(R_{i, i+1} P_{i}+X_{i, i+1} Q_{i}\right)+\left(R_{i, i+1}^{2}+X_{i, i+1}^{2}\right) \frac{P_{i}^{2}+Q_{i}^{2}}{V_{i}^{2}}
$$

where,

$\mathrm{S}_{\mathrm{i}}, \mathrm{S}_{\mathrm{i}, \max }$ are apparent power and maximum capacity limit of branch $\mathrm{i}$;

$\mathrm{V}_{\mathrm{i}}$ is voltage magnitude of bus $\mathrm{i}$;

$\mathrm{V}_{\mathrm{i}, \text { min }}$ and $\mathrm{V}_{\mathrm{i}, \max }$ are minimum and maximum voltage limits of bus.

$R_{j}$ is resistance of the $j^{\text {th }}$ branch

$P_{i}$ and $Q_{i}$ are the real and reactive powers that flow out of bus $\mathrm{i}$;

$\mathrm{P}_{\mathrm{Li}}$ and $\mathrm{Q}_{\mathrm{Li}}$ are the real and reactive load powers in bus $\mathrm{i}$ The resistance and reactance of the line section between buses $\mathrm{i}$ and $\mathrm{i}+1$ are denoted by $\mathrm{R}_{\mathrm{i}, \mathrm{i}+1}$ and $\mathrm{X}_{\mathrm{i}, \mathrm{i}+1}$ respectively.

$$
\frac{y_{i}}{2} \text { is the shunt capacitor connected at bus i }
$$

The minimization of total system real power loss is obtained by altering the open/closed status of switches.

\section{HYBRID TECHNOLOGY}

\subsection{Responsibility of PGSA}

As per [13], independent loops are decided as the decision variables, which can greatly reduce the dimension of the variables in the solved model and avoids unfeasible solutions. The new decision variables of an IEEE 33 bus distribution system shown in Fig. 2, which consists of 32 sectionalizing switches and five tie switches is given in equation (7). In equation (7), $\mathrm{L}_{1}-\mathrm{L}_{5}$ indicates independent loops and $S_{1}$ to $S_{37}$ indicates swiches. The initial tie switches are represented by dotted lines and sectionalizing switches by straight lines.

$$
\left.\begin{array}{l}
\mathrm{L}_{1}=\left\{\mathrm{S}_{2}, \mathrm{~S}_{3}, \mathrm{~S}_{4}, \mathrm{~S}_{5}, \mathrm{~S}_{6}, \mathrm{~S}_{7}, \mathrm{~S}_{33}, \mathrm{~S}_{20}, \mathrm{~S}_{19}, \mathrm{~S}_{18}\right\} \\
\mathrm{L}_{2}=\left\{\mathrm{S}_{8}, \mathrm{~S}_{9}, \mathrm{~S}_{10}, \mathrm{~S}_{11}, \mathrm{~S}_{35}, \mathrm{~S}_{21}, \mathrm{~S}_{33}\right\} \\
\mathrm{L}_{3}=\left\{\mathrm{S}_{9}, \mathrm{~S}_{10}, \mathrm{~S}_{11}, \mathrm{~S}_{12}, \mathrm{~S}_{13}, \mathrm{~S}_{14}, \mathrm{~S}_{34}\right\} \\
\mathrm{L}_{4}=\left\{\mathrm{S}_{3}, \mathrm{~S}_{4}, \mathrm{~S}_{5}, \mathrm{~S}_{25}, \mathrm{~S}_{26}, \mathrm{~S}_{27}, \mathrm{~S}_{28}, \mathrm{~S}_{37}, \mathrm{~S}_{22}, \mathrm{~S}_{23}, \mathrm{~S}_{24}\right\} \\
\mathrm{L}_{5}=\left\{\mathrm{S}_{6}, \mathrm{~S}_{7}, \mathrm{~S}_{8}, \mathrm{~S}_{34}, \mathrm{~S}_{15}, \mathrm{~S}_{16}, \mathrm{~S}_{17}, \mathrm{~S}_{36}, \mathrm{~S}_{32}, \mathrm{~S}_{31}, \mathrm{~S}_{30}, \mathrm{~S}_{29}, \mathrm{~S}_{28}, \mathrm{~S}_{27}, \mathrm{~S}_{26}, \mathrm{~S}_{25}\right\}
\end{array}\right\}
$$

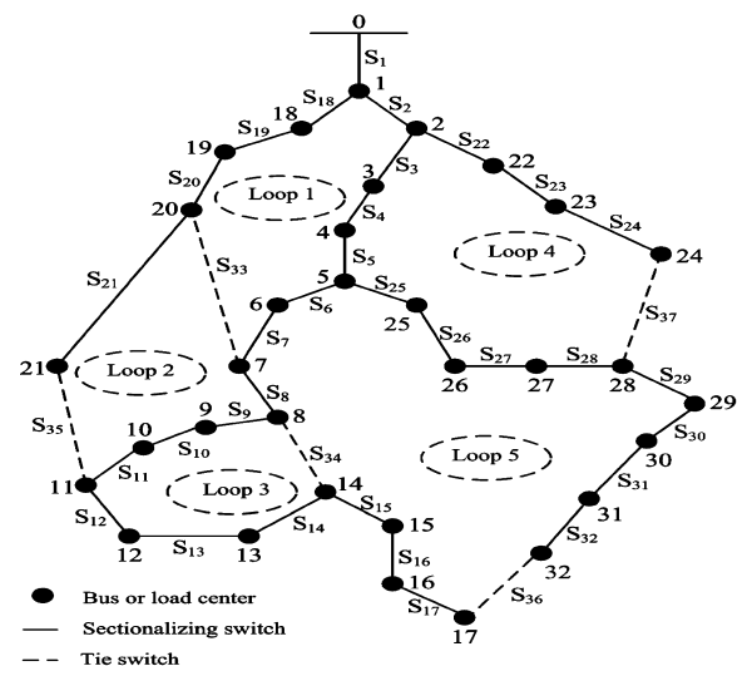

Fig. 2 The IEEE 33-bus sample system with loop numbers (Test System 1)

The solution sets are further reduced based on four states [13] to avoid unfeasible solutions in the iterative procedure. The possible solution sets are reduced as follows,

$$
\left.\begin{array}{l}
\mathrm{L}_{1}=\left\{\mathrm{S}_{4}, \mathrm{~S}_{5}, \mathrm{~S}_{6}, \mathrm{~S}_{7}, \mathrm{~S}_{20}, \mathrm{~S}_{19}\right\} \\
\mathrm{L}_{2}=\left\{\mathrm{S}_{8}, \mathrm{~S}_{9}, \mathrm{~S}_{10}, \mathrm{~S}_{11}, \mathrm{~S}_{21}\right\} \\
\mathrm{L}_{3}=\left\{\mathrm{S}_{12}, \mathrm{~S}_{13}, \mathrm{~S}_{14}\right\} \\
\mathrm{L}_{4}=\left\{\mathrm{S}_{25}, \mathrm{~S}_{26}, \mathrm{~S}_{27}, \mathrm{~S}_{28}, \mathrm{~S}_{23}, \mathrm{~S}_{24}\right\} \\
\mathrm{L}_{5}=\left\{\mathrm{S}_{15}, \mathrm{~S}_{16}, \mathrm{~S}_{17}, \mathrm{~S}_{32}, \mathrm{~S}_{31}, \mathrm{~S}_{30}, \mathrm{~S}_{29}\right\}
\end{array}\right\}
$$

For the searching process, loop sequencing has been considered as the most important. The distribution system with ' $n$ ' loops will produce $n$ ! possible loop sequences. The random/incorrect selection of loop sequence on occasion ends with local optimum. To make sure global optimum, in this paper greedy algorithm has been incorporated for identifying the best loop sequence.

As per the heuristic exchange rule (Kun-Yuan Huang and HongChan Chin, 2002) for growth points searching, the loss change resulting from switch exchange between Feeder-I and Feeder-II of the system is given by,

$$
\Delta P=2 I(x)\left(E_{m}-E_{n}\right)+R_{l o o p}[I(x)]^{2}
$$

where $\Delta \mathrm{P}$ is the power loss reduction/increase when it is negative/positive; $\mathrm{I}(\mathrm{x})$ is the current distribution along the shortest path; $\mathrm{x}$ is the distance from the opened switch to the tie bus; Em is the terminal bus voltage of the Feeder-I before the load transfer; En is the terminal bus voltage of the Feeder-II before the load transfer and Rloop is the series resistance of the path connecting the two substation buses of Feeder-I and Feeder-II. Due to the quadratic nature of $\Delta \mathrm{P}$, the optimal distance current $\mathrm{I}\left(\mathrm{x}_{\mathrm{opt}}\right)$ can be shown and described as follows,

$$
I\left(x_{\text {opt }}\right)=\frac{\left(E_{m}-E_{n}\right)}{R_{\text {loop }}}
$$

Therefore the minimum power loss can be obtained by substituting equation (10) in equation (9). It can be established as follows,

$$
\Delta P_{\min }=-\frac{\left(E_{m}-E_{n}\right)^{2}}{R_{\text {loop }}}
$$

From the equation (11), it is clear that larger the value of $\mathrm{I}\left(\mathrm{x}_{\mathrm{opt}}\right)$ will yield the greatest loss reduction among the candidates. Therefore, for reconfiguration the loops can be sequenced in the decreasing order of $\mathrm{I}\left(\mathrm{x}_{\mathrm{opt}}\right)$ of each loop. 
3.2 Sequencing of Loops through Optimum Transferable Current with Greedy

For the reconfiguration problem, the formation of problem and solution has been made as, (i) Candidate set, set of loops $\left\{\mathrm{L}_{1}, \mathrm{~L}_{2}, \mathrm{~L}_{3}, \mathrm{~L}_{4}, \mathrm{~L}_{5}\right\}$ in $\mathrm{RDS}$ referring Fig. 2; (ii) Selection function, Sequencing loops in decreasing order of Optimum Transferable Current (Iotc) of each loop; (iii) Feasibility function, Function which checks existence of loops in network and existence of switches in each loop; (iv) Objective function, Traverse all the loops of network one by one in sequence; (v) Solution function, Terminate process after some iteration or condition.

\subsection{Heuristic Fuzzy}

In order to address the power flow constraints along with power loss, heuristic fuzzy has been incorporated with PGSA and Greedy. In fuzzy domain, each parameter is associated with a membership function. There are three fuzzy-set models developed for optimization. They are responsible for restricting any configuration from bus voltage deviation, branch current deviation and increase in real power loss.

\subsubsection{Fuzzy-set model of the bus voltage deviations}

The voltage at the buses must be maintained within the permissible limits for each new configuration. It is defined as,

$$
\mathrm{V}_{\text {min }}<\mathrm{V}_{\text {new }, \mathrm{i}}<\mathrm{V}_{\text {max }} \text { for } \mathrm{i}=1,2,3, \ldots \ldots . \mathrm{n} \text {; }
$$

where,

$\mathrm{n}$ is the total number of buses present in the RDS

$\mathrm{V}_{\text {new }, \mathrm{i}}$ is $\mathrm{i}^{\text {th }}$ bus new configuration voltage

$\mathrm{V}_{\min }=0.9 \mathrm{pu}$ and $\mathrm{V}_{\max }=1$ pu have been considered

The new configurations bus voltages are compared with the voltage limit. The voltage at the buses has been obtained from radial load flow for each new configuration. Moreover, the amount of the $\mathrm{V}_{\text {new, } \mathrm{i}}$ resulting from any branch exchange can be estimated as 'very close', 'close' or 'not close' to the $\mathrm{V}_{\min }$. Therefore, the linguistic terms can be formulated as a membership function by the fuzzy notation. The membership function can be expressed as follows,

$$
\mu V, n= \begin{cases}1 & \text { for } \Delta V_{n}=0 \\ 1-\frac{\Delta V_{n}}{V \min } & \text { for } \Delta V_{n}>0 \quad \& \& \text { Vnew, } n<V \text { max } \\ 0 & \text { for otherwise }\end{cases}
$$

where,

$$
\Delta \mathrm{V}_{\mathrm{n}}=\mathrm{V}_{\text {new }, \mathrm{n}}-\mathrm{V}_{\min }
$$

$\mathrm{V}_{\text {new,nn }}$ is the system voltage at the $\mathrm{n}^{\text {th }}$ bus after reconfiguration.

The minimum amongst the membership values of voltage of all the bus in the system is obtained after reconfiguration.

$$
\mu_{\mathrm{v}}=\min \left\{\mu_{\mathrm{v}, 1}, \mu_{\mathrm{v}, 2}, \ldots \ldots \ldots \mu_{\mathrm{v}, \mathrm{n}}\right\}
$$

\subsubsection{Fuzzy-set model of the branch current loading}

The main purpose of this membership function is to determine the branch current loading during each new configuration. Initially, all the branches current capacity are defined as $I_{\text {set, } i}$; where, $i=1,2,3 \ldots . n$; $n$ is the total number of branches in the RDS. During each new configuration the new value of branch currents are received through Radial Load Flow (RLF) and defined as $\mathrm{I}_{i}$; where $\mathrm{i}=1,2,3 \ldots \mathrm{n} ; \mathrm{n}$ is the total number of branches.

The small difference between $I_{\text {set,i }}$ and $I_{i}$ are estimated and deviation of $I_{\text {set, } i}$ with $I_{i}$ set as 'very close', 'close' or 'not close'. The membership function of the $\mathrm{n}^{\text {th }}$ branch $\mu_{\mathrm{B}, \mathrm{n}}$, can be defined as,

$$
\mu_{B, n}= \begin{cases}1 & \text { for } \Delta I_{n}=0 \\ 1+\frac{\Delta I_{n}}{I_{\text {set }, n}} & \text { for } \quad \Delta I_{n}<0 \\ 0 & \text { for } \text { otherwise }\end{cases}
$$

where,

$$
\Delta \mathrm{I}_{\mathrm{n}}=\mathrm{I}_{\mathrm{n}}-\mathrm{I}_{\mathrm{set}, \mathrm{n}}
$$

The membership function of all the branches can be similarly expressed as equation (18). A large current variation $\Delta \mathrm{I}_{\mathrm{n}}$, produce a small value of the membership function $\mu_{\mathrm{B}, \mathrm{n}}$ and vice versa.

The branch loading level of the selected switch operation can further be defined when all the branches membership values are determined. It can be expressed as follows, $\mu_{\mathrm{B}}=\min \left[\mu_{\mathrm{B}, 1}, \mu_{\mathrm{B}, 2}, \ldots . \mu_{\mathrm{B}, \mathrm{n}}\right]$

where, $\mu_{\mathrm{B}}$ is the membership value after switching

\subsubsection{Fuzzy-set model of the real power loss}

The new configurations power loss $\left(\mathrm{P}_{\text {nloss }}\right)$ close to the previous configuration loss $\left(\mathrm{P}_{\text {tloss }}\right)$ to be identified for the objective of minimizing the system power loss. The power loss of the system has been obtained from RLF for each new configuration. Moreover, the amount of the $\mathrm{P}_{\text {nloss }}$ resulting from any branch exchange can be estimated as 'very close, 'close' or 'not close' to the $\mathrm{P}_{\text {tloss }}$.

Therefore, the linguistic terms can be formulated as a membership function by the fuzzy notation. The proposed membership function $\mu_{\mathrm{p}}$ has been depicted using equation (16). A small difference between $P_{\text {nloss }}$ and $P_{\text {tloss }}$ possesses a larger membership value. The membership function can be expressed as follows,

$$
\mu_{P}= \begin{cases}1 & \text { for } \Delta P=0 \\ 1+\frac{\Delta P}{P_{\text {toss }}} & \text { for } \quad \Delta P<0 \\ 0 & \text { for otherwise }\end{cases}
$$

where, $\quad \Delta \mathrm{P}=\mathrm{P}_{\text {nloss }}-\mathrm{P}_{\text {tloss }}$;

$\mathrm{P}_{\text {tloss }}$ is the system power loss before switching

The purpose of the feeder reconfiguration can be achieved by the decision fuzzy set $\mathrm{D}$, which is derived from the intersection of the three membership functions $\mu_{\mathrm{V}}, \mu_{\mathrm{B}}$ and $\mu_{\mathrm{P}}$. However, the optimal decision is the highest membership value of $\mu_{\mathrm{D}}$. Thus, an optimal decision fuzzy set $\mathrm{D}$ can be designated as follows,

$$
\mu_{\mathrm{D}}=\max \left\{\min \left[\mu_{\mathrm{v}}, \mu_{\mathrm{B}}, \mu_{\mathrm{P}}\right]\right\}
$$

\section{RECONFIGURATION SCHEME}

Reconfiguration scheme begins with finding the solution sets of the RDS. Then, total number of switches present in each set/loop has been calculated. With the use of greedy algorithm the best optimal loop sequence has been arrived by organizing the loops as on non-increasing order of $\mathrm{I}_{\mathrm{otc}}$.

The RDS real power loss and feeder currents pertain to respective configuration has been retrived through RLF. The membership values such as $\mu_{\mathrm{V}}, \mu_{\mathrm{B}}$ and $\mu_{\mathrm{P}}$ are calculated as per the membership function definitions shown in the equations (13), (15) and (16). For every individual loop of RDS [13], heuristic fuzzy produce different membership values and that are accumulated. Lastly, the accumulated data's are nourished to min-max imperative of fuzzy as per equation (17) and that defines best 
switch combinations for open/close in every individual loop. The same process has been repeated till there is no power loss change within the two consecutive iterations. Complete flow of proposed scheme for optimization has been revealed in the flowchart shown in Fig. 3. The ensuing configuration promisingly would be better than that of the initial configuration by means of loss reduction and feeder load balance.

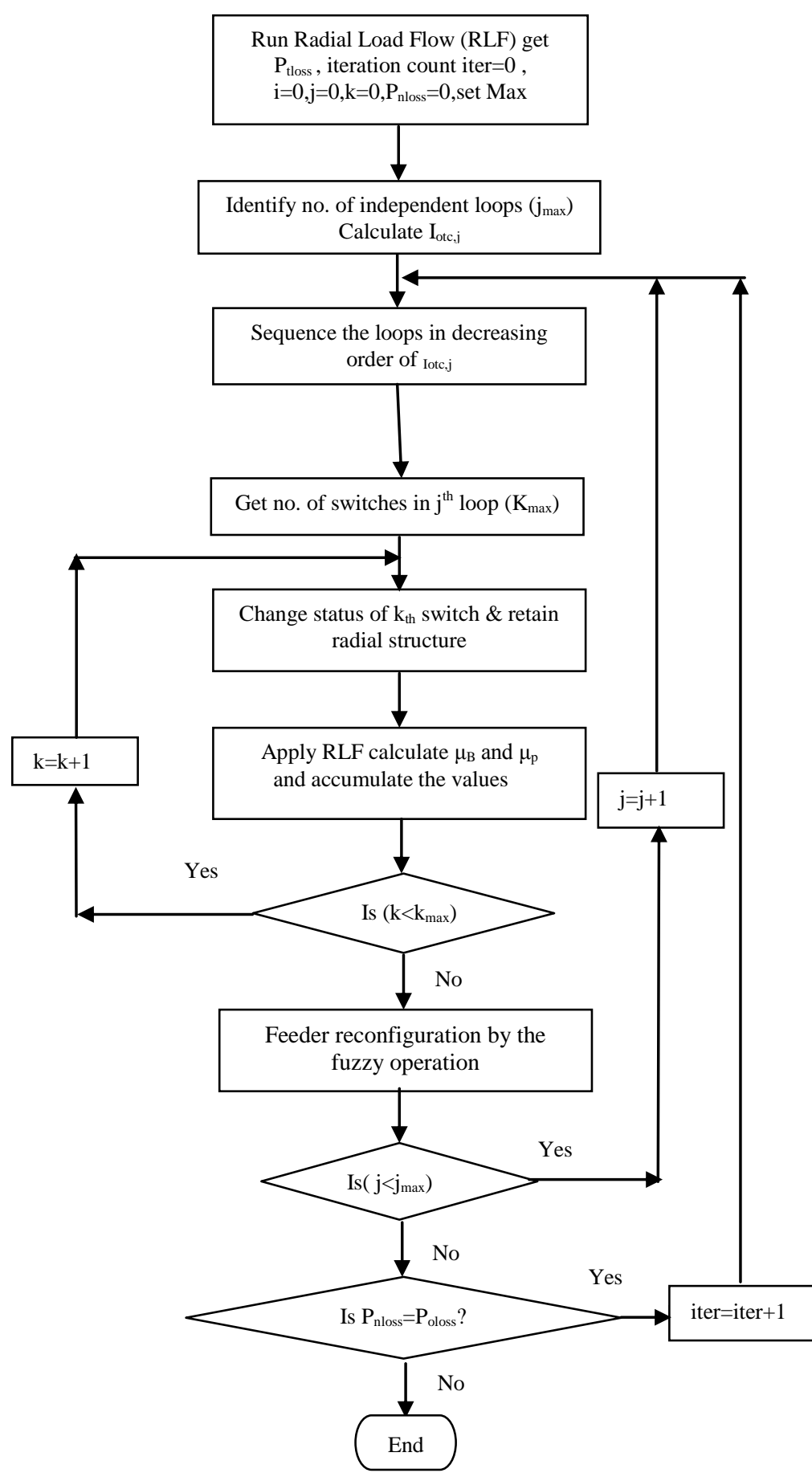

Fig. 3 Reconfiguration Algorithm with Hybrid Technology 5. RESULTS AND DISCUSSIONS

Software simulation has been done through servlet programming (Java 2 Enterprise Edition Programming) to decrease software couplings and enhance software quality and reusability. The simulation programs are implemented in P IV $2.4 \mathrm{GHz}$ computer.

\subsection{Soultion under normal condition of RDS}

\subsubsection{Depiction with Test System 1}

The proposed scheme has been tested on 33 bus RDS [13], which has 5 normally opened switches, 32 normally closed switches with 33 buses and it is assumed as balanced three-phase with $12.66 \mathrm{kV}$. The initial configuration and loop sequence followed in [13] is shown in Fig. 2. Initially, all the branches current capacity $\left(I_{\text {set }, \mathrm{i}}\right)$ are assumed (for $I_{\text {set }, 1}=500 \mathrm{~A}, I_{\text {set }, 2}=250 \mathrm{~A}$, from $I_{\text {set, } 3}$ to $I_{\text {set }, 37}$ current capacity was set as $150 \mathrm{~A}$ in accordance with system characteristic). The shunt capacitors are neglected. As per the PGSA, entity loops were identified with analogous state variables denoted as $\mathrm{L}_{1}, \mathrm{~L}_{2}, \mathrm{~L}_{3}, \mathrm{~L}_{4}$ and $\mathrm{L}_{5}$ declared in equation (8). The $\mathrm{I}_{\text {otc }}$ of loops are calculated as per equation (10). The values of $\mathrm{I}_{\text {otc. }}$ [for i E 1-5] are 107.15A, 152.98A, 49.43A, 119.52A and $8.20 \mathrm{~A}$ respectively. As per the greedy algorithm, the loop sequence has been made from the largest $\mathrm{I}_{\text {otc }}$ to smallest $\mathrm{I}_{\mathrm{otc}}$. It is identified that $\mathrm{I}_{\mathrm{otc}}$ value of loop 2 is largest. Therefore, searching begins from second loop. The corresponding analogous state variables are updated and shown in Fig. 3.

$$
\begin{aligned}
& \text { Loop } 1 \text { (III), } \mathrm{L}_{1}=\left\{\mathrm{S}_{4}, \mathrm{~S}_{5}, \mathrm{~S}_{6}, \mathrm{~S}_{7}, \mathrm{~S}_{20}, \mathrm{~S}_{19}\right\} \\
& \text { Loop } 2 \text { (I), } \mathrm{L}_{2}=\left\{\mathrm{S}_{8}, \mathrm{~S}_{9}, \mathrm{~S}_{10}, \mathrm{~S}_{11}, \mathrm{~S}_{21}\right\} \\
& \text { Loop } 3 \text { (IV), } \mathrm{L}_{3}=\left\{\mathrm{S}_{12}, \mathrm{~S}_{13}, \mathrm{~S}_{14}\right\} \\
& \text { Loop } 4 \text { (II), } \mathrm{L}_{4}=\left\{\mathrm{S}_{25}, \mathrm{~S}_{26}, \mathrm{~S}_{27}, \mathrm{~S}_{28}, \mathrm{~S}_{23}, \mathrm{~S}_{24}\right\} \\
& \text { Loop } 5 \text { (V), } \mathrm{L}_{5}=\left\{\mathrm{S}_{15}, \mathrm{~S}_{16}, \mathrm{~S}_{17}, \mathrm{~S}_{32}, \mathrm{~S}_{31}, \mathrm{~S}_{30}, \mathrm{~S}_{29}\right\}
\end{aligned}
$$

Search over RDS starts from $\mathrm{L}_{1}$ which yields 5 different combinations of open/close pair. The membership values of the switching operations significant to the different combinations are listed in the Table 1. From Table 1, after applying min-max imperative, it is observed that opening of $S_{9}$ and closing of $S_{35}$ produces much better configuration with reduced system loss of $153.98 \mathrm{~kW}$, current at the branches and voltage at the buses within the limits.

\section{Table 1 Membership values for the set $L_{1}$}

\begin{tabular}{|c|c|c|c|c|}
\hline $\boldsymbol{\mu}_{\mathbf{v}}$ & $\boldsymbol{\mu}_{\mathrm{p}}$ & $\boldsymbol{\mu}_{\mathrm{b}}$ & $\boldsymbol{\mu}_{\mathbf{d}}$ & $\begin{array}{c}\text { (Open/ } \\
\text { Close })\end{array}$ \\
\hline 0.9297 & 0.7573 & 0.8213 & 0.7573 & $\left(\mathrm{~S}_{8} / \mathrm{S}_{35}\right)$ \\
\hline 0.9287 & 0.7598 & 0.7856 & 0.7856 & $\left(\mathrm{~S}_{9} / \mathrm{S}_{35}\right)$ \\
\hline 0.9276 & 0.7654 & 0.7583 & 0.7583 & $\left(\mathrm{~S}_{10} / \mathrm{S}_{35}\right)$ \\
\hline 0.9267 & 0.7736 & 0.8199 & 0.7736 & $\left(\mathrm{~S}_{11} / \mathrm{S}_{35}\right)$ \\
\hline 0.9083 & 0.0 & 0.5600 & 0.0 & $\left(\mathrm{~S}_{21} / \mathrm{S}_{35}\right)$ \\
\hline
\end{tabular}

The same process has been repeated for the rest of the sets for the first iteration. The above said process is carried out with the primary focus on real power loss minimization. The power loss at the final configuration is $139.54 \mathrm{~kW}$.

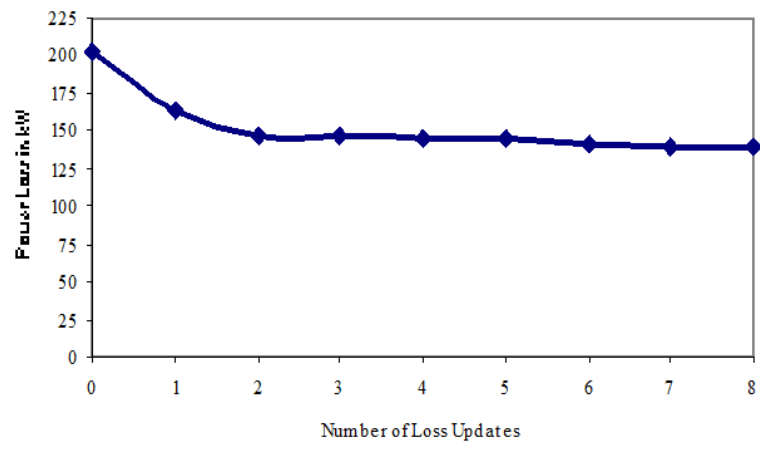


Fig. 4 Power loss updates of Test System I under normal condition as per Hybrid

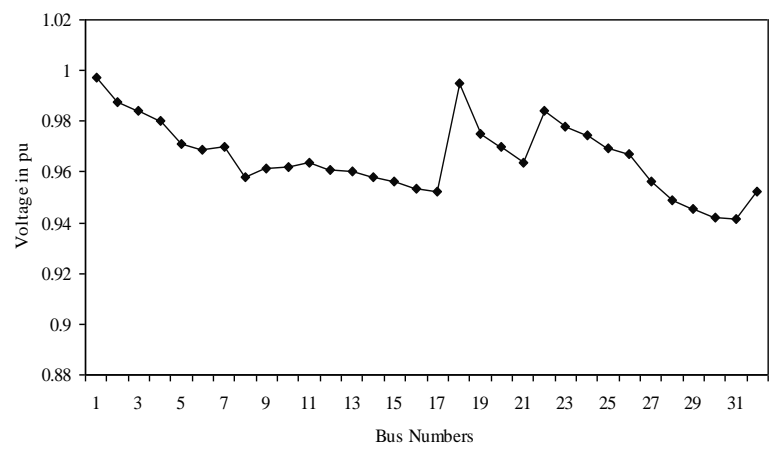

Fig. 5 Minimum bus voltage updates of Test System I under normal condition as per Hybrid

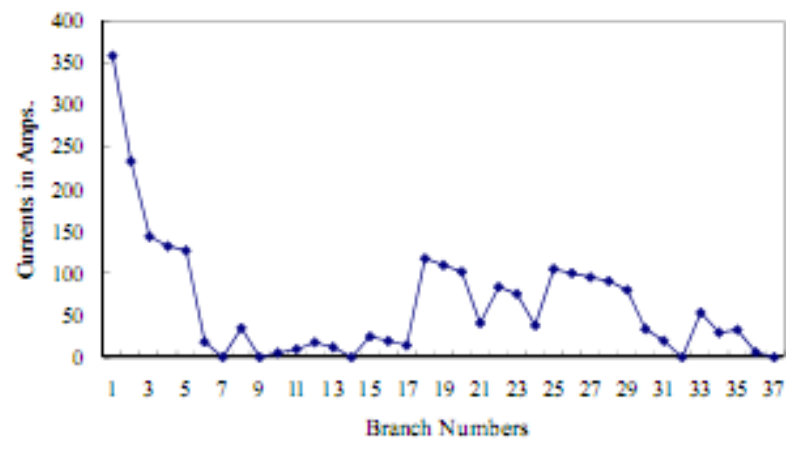

Fig. 6 Branches current updates of Test System I under normal condition as per Hybrid

The power loss updates is shown in Fig. 4. The branch currents and bus voltages are maintained within their limits. The branch currents and bus voltages at the final configuration are shown in Fig. 5 and Fig. 6. The identified switches to be opened at final configuration are $\mathrm{S}_{7}, \mathrm{~S}_{9}, \mathrm{~S}_{14}, \mathrm{~S}_{32}$ and $\mathrm{S}_{37}$.

\subsubsection{Test System II}

The proposed methodology has been applied next to the test system shown in Fig. 8 [13]. The system is assumed balanced three-phase with $11.4 \mathrm{kV}$. It consists of 11 feeders, 83 normally closed switches, 13 normally open switches and 13 loops. The shunt capacitors are neglected. For the loops, solution sets are named sequentially from $L_{1}$ to $L_{13}$.

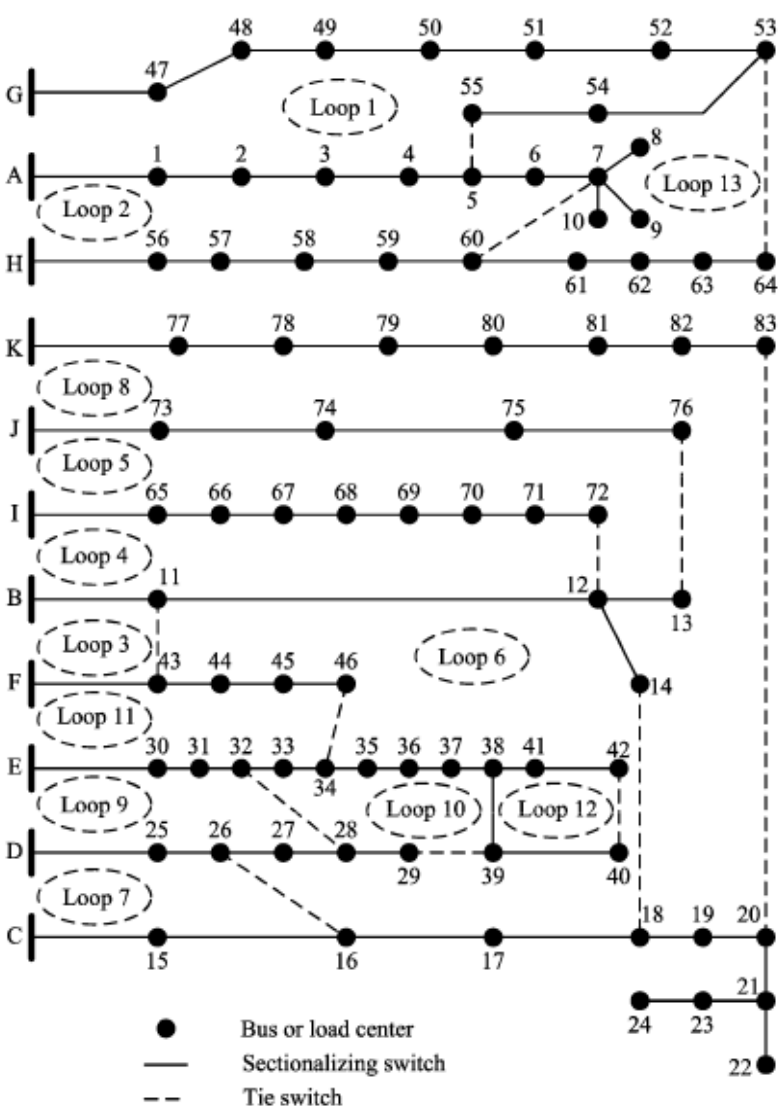

Fig. 7 Distribution system of Taiwan Power Company (Test System II)

As per the PGSA, decision variables are designed for the system shown in Fig. 7. The loops are sequenced based on decreasing order of Iotc (GrA). The maximum current capacity of the branches is $600 \mathrm{~A}$. The bus voltage limits are fixed as $\mathrm{V}_{\min }=0.9 \mathrm{pu}$ and $\mathrm{V}_{\max }=1.0 \mathrm{pu}$.

After applying the proposed methodology, the system loss is reduced from $542.55 \mathrm{~kW}$ to $469.88 \mathrm{~kW}$ which has been shown in Fig. 8, the minimum voltage is 0.9531 pu amongst all the buses and the branches current are maintained under limit.

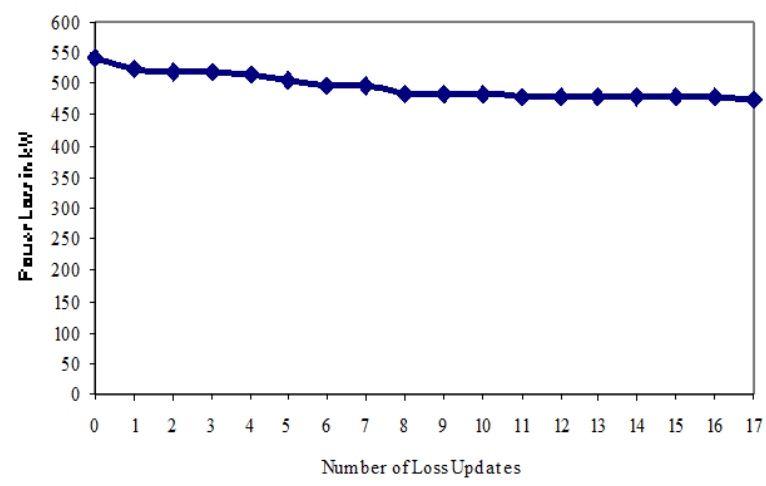

Fig. 8 Power loss updates of Test System II under typical condition as per Hybrid

The results obtained through proposed methodology have been compared with other technologies proposed earlier for reconfiguration in Table 2 for Test system I. The proposed algorithm obtains the global optimum within $90 \mathrm{msec}$. while PGSA takes $278 \mathrm{msec}$. for Test System I. 
Table 2 Simulation results of Test system I

\begin{tabular}{|c|c|c|c|c|c|}
\hline Items & $\begin{array}{c}\text { Initial } \\
\text { state } \\
\text { (normal } \\
\text { condition) }\end{array}$ & $\begin{array}{c}\text { Proposed } \\
\text { method } \\
\text { (Fuzzy- } \\
\text { GrA- } \\
\text { PGSA) }\end{array}$ & $\begin{array}{l}\text { Wang } \\
\text { and } \\
\text { Cheng } \\
(2008)\end{array}$ & $\begin{array}{c}\text { Goswami } \\
\text { and } \\
\text { Basu } \\
(1992)\end{array}$ & $\begin{array}{c}\text { Ying-Yi } \\
\text { and } \\
\text { Saw-Yu } \\
(2006)\end{array}$ \\
\hline $\begin{array}{l}\text { Ope } \\
\text { n } \\
\text { switc } \\
\text { hes }\end{array}$ & $\begin{array}{c}\mathrm{S}_{33}, \mathrm{~S}_{34} \\
\mathrm{~S}_{35}, \mathrm{~S}_{36} \\
\mathrm{~S}_{37}\end{array}$ & $\begin{array}{c}\mathrm{S}_{7}, \mathrm{~S}_{9} \\
\mathrm{~S}_{14}, \mathrm{~S}_{32} \\
\mathrm{~S}_{37}\end{array}$ & $\begin{array}{l}\mathrm{S}_{7} \\
\mathrm{~S}_{9} \\
\mathrm{~S}_{14}, \\
\mathrm{~S}_{32}, \\
\mathrm{~S}_{37}\end{array}$ & $\begin{array}{c}\mathrm{S}_{7}, \mathrm{~S}_{10} \\
\mathrm{~S}_{14}, \mathrm{~S}_{32} \\
\mathrm{~S}_{37}\end{array}$ & $\begin{array}{l}\mathrm{S}_{9}, \\
\mathrm{~S}_{28} \\
\mathrm{~S}_{33} \\
\mathrm{~S}_{34} \\
\mathrm{~S}_{36}\end{array}$ \\
\hline $\begin{array}{l}\text { Loss } \\
(\mathrm{kW})\end{array}$ & 202.7 & 139.4 & 139.4 & 141.5 & 140.6 \\
\hline
\end{tabular}

The results obtained through proposed methodology have been compared with other technologies proposed earlier for reconfiguration in Table 3 for Test system II. The proposed algorithm obtains the global optimum within $2.8 \mathrm{sec}$ while PGSA takes 3.9sec for Test System II. From the results, it is found that reconfiguration made through proposed algorithm receives global optimum with minimum time consumption and has taken multiple constraints.

Table 3 Simulation results of Test system II

\begin{tabular}{|c|c|c|c|c|}
\hline Items & $\begin{array}{c}\text { Initial } \\
\text { State } \\
\text { (Normal } \\
\text { Condition) }\end{array}$ & $\begin{array}{c}\text { Proposed } \\
\text { method } \\
\text { (Fuzzy- } \\
\text { GrA- } \\
\text { PGSA) }\end{array}$ & $\begin{array}{c}\text { Wang } \\
\text { and } \\
\text { Cheng } \\
\mathbf{( 2 0 0 8 )}\end{array}$ & $\begin{array}{c}\text { Ying- } \\
\text { Yi } \\
\text { and } \\
\text { Saw- } \\
\text { Yu } \\
(\mathbf{2 0 0 6})\end{array}$ \\
\hline $\begin{array}{c}\text { Loss } \\
(\mathrm{kW})\end{array}$ & 531.99 & 469.88 & 469.88 & 469.88 \\
\hline
\end{tabular}

Hence with the effective introduction of the hybrid reconfiguration algorithm, loss reduction was done subjected under constraints such as bus voltage limit and branch current limit.

\section{CONCLUSION}

An efficient approach that employs hybrid technology as optimal means has been presented for the reconfiguration of RDS, where the objective is loss reduction and subjected under constraints like branches current limit violation and buses voltage limit violation. The results have shown that reconfiguration has been attained with multi constraints under typical and strange conditions of RDS. The results obtained with the present approach, when compared with the previous methods proposed by the authors will show that the introduction of the algorithm with PGSA-Greedy-heuristic fuzzy has contributed to reduce the number of power flows and has incorporated the network constraints. Thus, the performance of the proposed hybrid technology has been considerably enhanced and can be applied to any large real RDS supplied from more feeders.

\section{ACKNOWLEDGEMENT}

The authors gratefully acknowledge the support and facilities provided by the authorities of their respective institutions to carry out this research work.

\section{REFERENCES}

[1] S. Civanlar, J. J. Grainger, H. Yin, and S. S. H. Lee, "Distribution feeder reconfiguration for loss reduction," IEEE Trans. Power Del., vol. 3, no. 3, pp. 1217-1223, Jul. 1988.

[2] Baran $\mathrm{ME}$ and $\mathrm{Wu} \mathrm{FF}$, 'Network reconfiguration in distribution systems for loss reduction and load balancing," IEEE Trans. Power Del., vol. 4, no. 1, pp. 4011407, Jan. 1989.

[3] Aoki K, Kawabara H, and Satoh. M, "An efficient algorithm for load balancing of transformers and feeders," IEEE Trans. Power Del., vol. 3, no. 4, pp. 18651872, Jul. 1988.

[4] D. Shirmohammadi and H.W. Hong, "Reconfiguration of electric distribution networks for resistive line losses reduction," IEEE Trans. Power Del., vol. 4, no. 2, pp. 1492 1498, Apr. 1989.

[5] Goswami .S.K and Basu .S.K (1992), "A new algorithm for the reconfiguration of distribution feeders for loss minimization", IEEE Trans. Power Del.,Vol.7, No.3, pp.1484-1490.

[6] Ying-Yi .H and Saw-Yu .H (2006), "Determination of network configuration considering multiobjective in distribution systems using genetic algorithms", IEEE Trans. on Power Sys., Vol. 20, No. 2, pp. 1062-1069.

[7] L. Whei-Min and C. Hong-Chan, "A new approach for distribution feeder reconfiguration for loss reduction and service restoration," IEEE Trans. Power Del., vol. 13, no. 3, pp. 870-875, Jul. 1998.

[8] H. Kim, Y. Ko, and K. H. Jung, "Artificial neural-network based feeder reconfiguration for loss reduction in distribution systems," IEEE Trans. Power Del., vol. 8, no. 3, pp. 13561366, Jul. 1993.

[9] H. Salazar, R. Gallego, and R. Romero, "Artificial neural networks and clustering techniques applied in the reconfiguration of distribution sys- tems," IEEE Trans. Power Del., vol. 21, no. 3, pp. 1735-1742, Jul. 2006.

[10] Liu CC, Lee SJ, Venkata SS, “An expert system operational aid for restoration and loss reduction of distribution systems," IEEE Trans. Power Del., vol. 3, no. 3, pp. 61925, Jan. 1988.

[11] B. Venkatesh, R. Ranjan, and H. B. Gooi, "Optimal reconfiguration of radial distribution systems to maximize loadability," IEEE Trans. Power Syst., vol. 19, no. 1, pp. 260-266, Feb. 2004.

[12] K. Huang and H. Chin, "Distribution feeder energy conservation by using heuristics fuzzy approach," Electrical Power and Energy Systems, vol. 24,pp. 439-445, 2002.

[13] C. Wang and H.Z. Cheng "Optimization of Network configuration in Large distribution systems using plant growth simulation algorithm," IEEE Trans. Power Syst., vol.23, No. 1, pp. 119-126, Feb. 2008.

[14] S. Thiruvenkadam, A. Nirmalkumar, \& M. Sathishkumar, "Distribution network optimization through fusion technology", Australian Journal of Electrical and Electronics Engg. vol.7, no. 2, pp. 145-152, 2010.

[15] Y. H. Song, G. S. Wang, A. T. Johns, and P. Y. Wang, "Distribution network reconfiguration for loss reduction using fuzzy controlled evolutionary programming," Proc. Inst. Elect. Eng., Gen., Transm., Distrib., vol. 144, no. 4, pp. 345-350, Jul. 1997. 
[16] A. C. B. Delbem, A. C. P. L. F. Carvalho, and N. G. Bretas, "Main chain representation for evolutionary algorithms applied to distribution system reconfiguration," IEEE Trans. Power Syst., vol. 20, no. 1, pp. 425-436, Feb. 2005.

[17] A. C. Neto, A. B. Rodrigues, R. B. Prada, and M. G. Silva, "External Equivalent for electric power distribution networks with radial topology," IEEE Trans. Power Syst., vol. 23, no. 3, pp. 889-895, Aug. 2008.

\section{AUTHORS PROFILE}

John Wiselin .M.C, corresponding author of the paper, was born in India. He received the B.E. degree in Electrical and Electronics Engineering from Manonmaniam Sundaranar University in 2002, the M.E. degree in Power Systems from Annamalai University in 2004 and doing his Ph.D. in Power Distribution System reconfiguration Currently, he is working as a
Associate Professor in the Department of Electrical and Electronics Engineering at Satyam College of Engg \& Tech, Aralvaimozhi,, Tamilnadu, India. He is a Life Member of ISTE. His research interests include power distribution systems, digital control techniques for power electronic circuits and power distribution systems.

Perumal Sankar received his B.E. in Electronics and Communication Engineering, M.E. in Communication Systems in Madurai Kamaraj Unviersity, India. He completed his $\mathrm{PhD}$ in Optical MEMS in Anna University, Chennai in 2008. He is currently working as Professor in M.E.T. Engineering College Chenbagaraman puthoor. His research interests include Communication systems and optimization techniques. 